\title{
Mental shock can produce retrograde amnesia
}

\author{
ELIZABETH F. LOFTUS and TERRENCE E. BURNS \\ University of Washington, Seattle, Washington 98195
}

\begin{abstract}
Subjects in three experiments saw a short film of a mentally shocking event in which a young boy is violently shot in the face. Compared to other subjects who saw a nonviolent version of the same film, those who saw the mentally shocking version showed poorer retention of the details of the film. Retention was poorer whether measured by recognition or recall. Furthermore, impaired memory occurred only when the event was mentally upsetting, and not when it was merely unexpected but not upsetting. These results suggest that mentally shocking episodes may disrupt the lingering processing necessary for full storage of information in memory.
\end{abstract}

Retrograde amnesia refers to the loss of memory for events that occur prior to some critical incident, such as a head injury, electroconvulsive stimulation, or the administration of a variety of drugs. The size of the memory deficit typically varies with the temporal interval between the earlier event and the critical incident. A leading interpretation of these results is that memory traces consolidate with the passage of time, and that a critical incident, such as an injury to the brain, can disrupt the process of consolidation (Deutsch $\&$ Deutsch, 1966). Other interpretations are also possible: for example, that the critical incident affects retrieval, rather than storage, of information in memory (Cotman \& McGaugh, 1980), or that it affects semantic or context encoding processes in some way (see Stern, 1981, for a review of these theories).

Nearly all of the work on retrograde amnesia with humans has involved an actual insult to the brain, whether by accidental injury (Goldberg, Antin, Bilder, Gerstman, Hughes, \& Mattis, 1981; Russell \& Nathan, 1946; Whitty \& Zangwill, 1977) or by deliberate administration of drugs, electroconvulsive therapy (Squire, 1975), or other intervention. One exception to this rule is a phenomenon that resembles retrograde amnesia that has been produced under laboratory conditions using memory for lists of common words. The critical incident in this case was the presentation of an unusual word, typically the name of a famous person, such as Columbus, Freud, or Aristotle (Tulving, 1969). In this

This research was supported by grants from the National Science Foundation and the National Bureau of Standards. Portions of this work were presented at the British Psychological Society meetings, Guilford, England, September 1981, and at the Psychonomic Society meetings, Philadephia, November 1981. We thank Ilene Bernstein, Richard Hammersley, Earl B. Hunt, Marcel Kinsbourne, John Morton, Michael Stanton, and Endel Tulving for helpful comments and suggestions. Carla Iafrati provided valuable help at various stages of data collection. Please address all correspondence to Elizabeth Loftus, Department of Psychology, University of Washington, Seattle, Washington 98195. research, and in studies that were stimulated by it (e.g., Saufley \& Winograd, 1970; Schulz, 1971), significant decrements in recall of items that precede a critical name have been consistently observed. These results are generally interpreted as providing support for some version of the consolidation hypothesis (Tulving, 1969). Of course, it should be kept in mind that the resemblance between the retrograde effects observed in these studies and the retrograde effects that have been associated with physical insult to the brain in no way indicates that a common mechanism lies at the heart of the two retrograde effects.

The phenomenon of retrograde amnesia is of great theoretical importance, and to advance our understanding of it, we must find ways of producing the phenomenon in laboratory settings that more naturally mirror the information processing demands of real-life situations. We describe here three experiments, involving 566 subjects, that demonstrate retrograde amnesia in human beings who are exposed to mentally, but not physically, shocking experiences that are realistic in nature. A major goal of this work was to demonstrate the existence of retrograde effects with highly realistic material. Once achieved, we explored some characteristics of the retrograde effect obtained with these materials.

\section{EXPERIMENT 1}

\section{Method}

Subjects. The subjects were 266 students at the University of Washington. They participated in small groups, and this participation satisfied a course requirement. They were told that they were free to leave the experiment at any time and still receive full credit, but none of them chose to do so.

Materials. Subjects viewed a film of a bank robbery lasting approximately $2.25 \mathrm{~min}$. The film is part of a training program designed to instruct employees on how to react in the event of a robbery. The film clip was taken from 3:57 Friday Afternoon, produced by the Idaho First National Bank in 1977. The robbery portrayed in the film is the type that occurs most frequently, in which a lone individual holds up a single teller. After robbing the teller, the robber walks quickly out of the bank. The teller shouts that she has just been robbed, and two male employees chase the robber into a parking lot where two 
young boys are playing. In the violent version of the film, as the robber runs toward a getaway car, he turns and fires a shot toward the two men in pursuit. The shot hits one of the boys in the face and he falls to the ground bleeding, his hands clutching his face. In the nonviolent version, the events are identical until just prior to the shooting, when the film flashes back to the inside of the bank, where the manager is informing the employees and customers about what has happened and asking everyone to stay calm. The two endings are approximately $15 \mathrm{sec}$ in length.

Design and Procedure. The film was shown using a .75-in. video cassette player, with 115 subjects viewing the violent version and 111 viewing the nonviolent version. Immediately after viewing the film, they answered a set of 25 multiple-choice and fill-in-the-blank questions. After each question, they indicated their confidence in their answers by choosing a number from 1 (indicating "guessing") to 5 (indicating "very sure"). The last question was critical. It asked the number on the football jersey of one of the young boys who was playing in the parking lot, and it required the subject to fill in the blank with the answer. The correct number was 17 ; it could be seen for a total of $2 \mathrm{sec}$, and specifically from $4 \mathrm{sec}$ to $2 \mathrm{sec}$ prior to the critical incident (the shooting in the violent case, the return to the bank in the nonviolent case). A still shot from the videotape, showing the boy and the number 17 just prior to the critical incident, is shown in Figure 1.

Included on the questionnaire were two personal questions, one referring to the interest level and the other asking about how upsetting the viewing of the videotape was for the subject. These two questions were answered on a scale from 1 (indicating "least interesting" or "least upsetting") to 5 (indicating "most interesting" or "most upsetting"). The experiment lasted approximately $30 \mathrm{~min}$.

\section{Results}

The results for the critical item were dramatic: Sub. jects were far less likely to recall the number on the boy's jersey when its appearance preceded the eruption of violence than when it did not. Only $4.3 \%$ of the subjects correctly recalled the number in the violent condition, whereas $27.9 \%$ recalled it in the nonviolent condition $\left[\chi^{2}(1)=21.72, p<.001\right]$. Subjects were marginally more confident in their answers to this item in the nonviolent than in the violent condition [ $1.69 \mathrm{vs}$. $1.41 ; \mathrm{t}(224)=1.79, \mathrm{p}<.07]$.

In analyzing the results, we also considered performance on the filler items, but we confined our analysis to those items on the questionnaire that could only be answered with information presented in the identical portion of the film, that is, the time prior to the critical incident. Thus, an item such as "What was the color of the carpeting in the bank?" was excluded from this analysis, since the carpeting could be seen again in the nonviolent version, when the scene returned to the

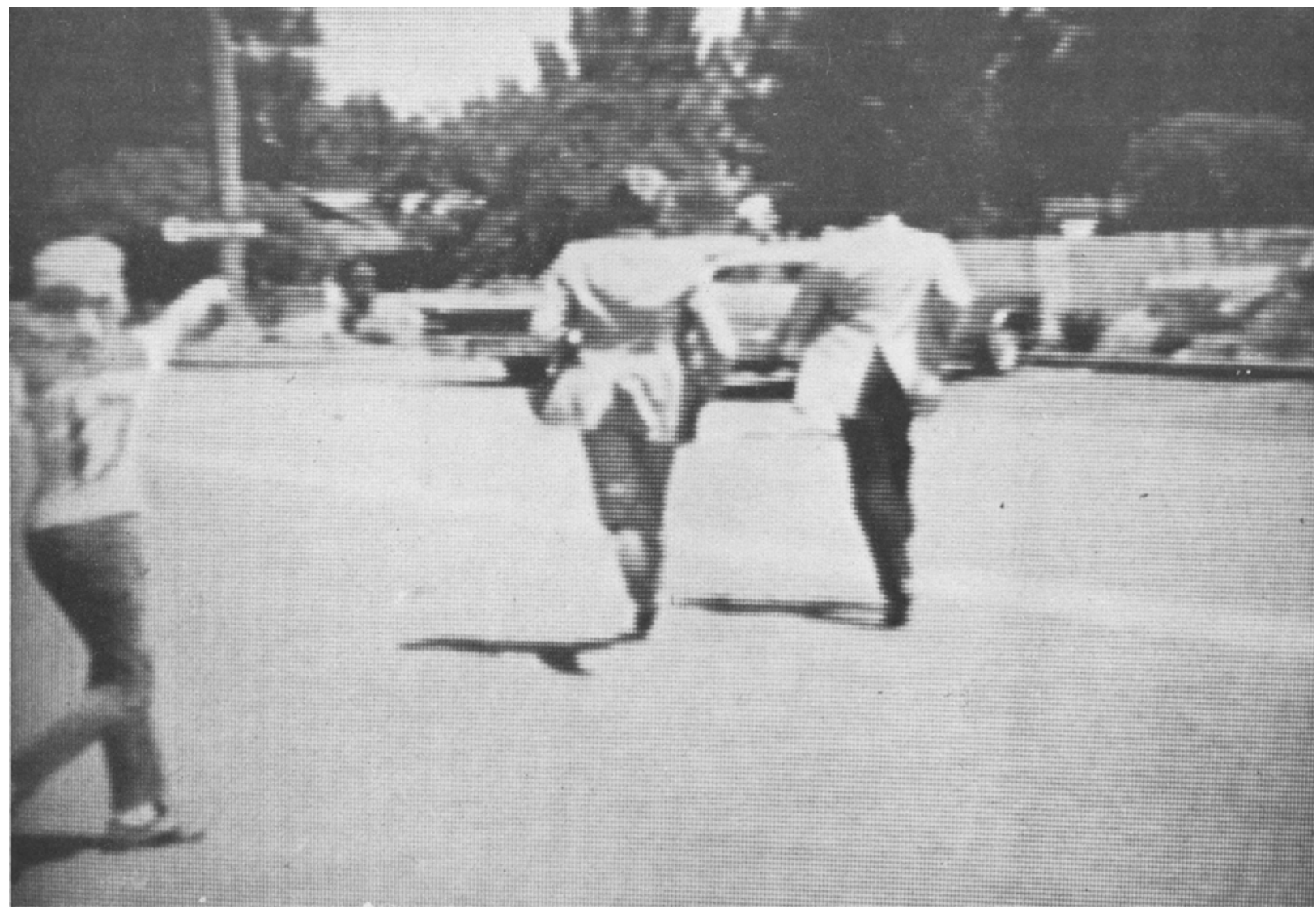

Figure 1. Black-and-white representation of scene viewed by subjects, showing boy with the number 17 on his football jersey. 
inside of the bank. Subjects who viewed the nonviolent version would obviously have an advantage on this item, which we wished to avoid. There were 16 filler items that could be answered only with information presented in the identical portion of the film, and 14 of them were answered correctly more often when subjects had viewed the nonviolent rather than the violent version $(p<.05$, by a sign test). A brief description of these items and performance on them for the two groups of subjects is shown in Table 1. They are listed in the order in which subjects answered them, which approximates the order in which information about them was presented in the film. It should be kept in mind that most of these items referred to information that was presented several times during the film, and over extended periods of time at that. For example, the question "What was the color of the robber's eyes?" or "How many men chased the robber?" could be answered with information obtained at multiple points in time during the film. However, the critical item about the number on the boy's football jersey appeared only once and for a brief period of time. Thus, although it appears as if responding to the item that occurred immediately before the critical incident was affected much more than responding to those items that occurred earlier in the film (suggesting a temporally graded effect), this cannot be conclusively assumed because of the noncomparability of the items.

Table 1 also contains confidence ratings for each item. It can be seen that for 14 of 16 filler items, as well as the critical item, subjects who viewed the nonviolent version were more confident of their answers.

Finally, as expected, subjects found the experiment to be far more upsetting in the violent condition than in the nonviolent condition $[3.30$ vs. $1.77 ; \mathrm{t}(224)=10.68$, $\mathrm{p}<.001]$, and they rated it as significantly more interesting [3.77 vs. $3.50 ; \mathrm{t}(224)=2.11, \mathrm{p}<.03]$.

Table 1

Percent Correct (PC) and Mean Confidence Ratings (CR) in Experiment 1

\begin{tabular}{lccccc}
\hline & \multicolumn{2}{c}{ Violent } & & \multicolumn{2}{c}{ Nonviolent } \\
\cline { 2 - 3 } \cline { 5 - 6 } \multicolumn{1}{c}{ Item } & PC & CR & & PC & CR \\
\hline Day of week & 91.3 & 4.47 & & 85.6 & 4.59 \\
Time of day & 73.0 & 4.50 & & 75.7 & 4.68 \\
Color robber's hair & 98.3 & 4.42 & & 99.1 & 4.49 \\
Robber moustache? & 88.7 & 4.17 & & 89.2 & 4.19 \\
Color robber's eyes & 62.6 & 2.18 & & 82.0 & 2.31 \\
Robber glasses? & 93.0 & 4.51 & & 93.7 & 4.63 \\
Robber's clothes & 79.1 & 4.39 & & 82.0 & 4.32 \\
Robber's shirt & 16.5 & 2.84 & & 25.2 & 2.93 \\
Note to teller & 91.3 & 4.56 & & 94.6 & 4.81 \\
Teller put money & 91.3 & 4.58 & & 93.7 & 4.66 \\
Robber's words & 80.9 & 3.66 & & 86.5 & 3.93 \\
Alarm button & 93.0 & 4.62 & & 91.9 & 4.64 \\
Robber's expression & 63.5 & 3.18 & & 76.6 & 3.63 \\
Number employees & 94.8 & 4.68 & & 99.1 & 4.78 \\
First man out & 78.3 & 3.50 & & 81.1 & 3.48 \\
Direction out bank & 86.1 & 4.34 & & 91.9 & 4.37 \\
Number on jersey & 4.3 & 1.41 & & 27.9 & 1.69 \\
\hline
\end{tabular}

Note-The last item was the critical item.

\section{Discussion}

In Experiment 1, we found that subjects who viewed a violent version of an event were less able than control subjects to remember details that occurred prior to the eruption of the violence. It is impossible to disentangle whether this impairment in memory was because of a failure to store the pertinent information or because of an inability to retrieve it later. Experiment 2 was conducted, in part, to address this question.

\section{EXPERIMENT 2}

The primary purpose of this experiment was to determine whether exposure to the violent film segment would produce retrograde amnesia with a recognition task, as it did with a recall task in Experiment 1. However, it had as a secondary purpose to assess the viability of an alternate explanation for the effects obtained in the first study.

Experiment 2 was essentially a replication of Experiment 1 , with two important modifications. First, the critical item was tested with a recognition test question rather than a recall test question. Subjects were asked to designate the number on the football jersey by choosing one of four alternatives: $10,13,1$, and 17 . The rationale for this modification was that if retrograde amnesia is caused by a failure of initial registration or encoding of the event into memory, then detrimental effects of mental shock should be apparent when subjects are tested via recognition as well as recall. On the other hand, if retrograde amnesia is caused by a breakdown of the retrieval of adequately stored information, then detrimental effects might not appear when subjects are tested via recognition, because recognition minimizes the need for retrieval.

A second change in this experiment was the addition of a third version of the event. It could be argued that the results depended upon the particular nonviolent version that we created. It happened that the version we used terminated the "parking lot" episode of the plot and presented the subject with a new "back in the bank" episode. In contrast, the violent version continued in the parking lot. It is possible that details from different episodes within an overall story may simply interfere with each other less. To explore this possibility, we created a third version of the film, in which, in place of the shooting scene, a police car arrives in the parking lot and some conversation follows. It was identical in length to the other two endings.

\section{Method}

Subjects were 180 students who participated in this study as a filler activity in conjunction with another, unrelated experiment. Because of time constraints, subjects first saw one of three versions of the film (violent, nonviolent-bank, and nonviolentpolice) and then engaged in a short unrelated activity. Finally, they answered the critical item about the number on the football jersey. As indicated earlier, they responded to a fouralternative forced-choice recognition item. 


\section{Results}

As in Experiment 1, subjects were far less likely to remember the number on the football jersey when its appearance preceded an eruption of violence than when it did not. Only $28 \%$ of the subjects responded correctly in the violent condition, whereas $55 \%$ and $52 \%$ of the subjects responded correctly in the nonviolent-bank and nonviolent-police conditions, respectively. The smaller of these two figures, $52 \%$, is significantly different from the violent-film group's performance of $28 \%$ by a wide margin $\left[\chi^{2}(1)=6.81, p<.01\right]$. It should be kept in mind that the four-alternative forced-choice test item yields $25 \%$ correct recognition by chance alone. Thus, the performance of those who viewed the violent version did not exceed chance level, whereas the performance of those who viewed the nonviolent versions was considerably better than chance.

\section{Discussion}

Experiment 2 demonstrates that the viewing of a violent event affects not only the recall of information but recognition as well. Some investigators might contend that this result argues against retrieval failure as an explanation of the retrograde effect. For example, Detterman and Ellis (1972) have specifically stated that "failure to demonstrate retrograde amnesia using a recognition task would ... [seem] to argue for retrieval failure as the origin of retrograde amnesia" (p. 315). However, this conclusion assumes that recognition involves little or no retrieval whatsoever, and this assumption is certainly controversial. (See Baddeley, 1976, for a discussion of this aspect of recall vs. recognition.) Certainly there was much more relevant retrieval information for the critical to-be-remembered detail without even suggestive evidence for any attenuation of the major effect observed in Experiment 1.

A rather conservative interpretation of the results of Experiment 2 is that the retrograde effect in the violent condition is sufficiently strong that it appears not to matter whether the subject is tested via recall or recognition, suggesting we have a profound effect, indeed. Of course, it is possible that there is some aspect of the violent version, other than its sheer violence, that is responsible for the impairment in memory. For example, one could argue that the violent version of the event may have been quite unexpected, and perhaps any unexpected change, whether violent or not, would produce a similar retrograde amnesia for the critical item. To test this possibility, a third experiment was conducted.

\section{EXPERIMENT 3}

Experiment 3 used three groups of subjects. One group of 55 subjects saw the violent version that had been shown in previous experiments, and a second group of 53 subjects saw the nonviolent-bank version. A third group of 52 subjects saw a new version containing an unexpected, but nonviolent, ending. In this version, the scene shifts at the critical moment, just prior to the shooting scene in the violent version, to a completely different film clip showing two people at a distance walking along the beach. This ending, like the other two, was approximately $15 \mathrm{sec}$ in length.

In all other ways, the experiment was identical to the previous one: Subjects saw the event, engaged in a 10-min filler activity, and then answered the critical question about the number on the football jersey. Again, their memory was measured via their response to a fouralternative forced-choice item.

As in the other experiments, subjects were far less likely to remember the number on the football jersey when its appearance preceded an eruption of violence than when it did not. Only $24 \%$ of the subjects responded correctly in the violent condition, whereas $47 \%$ and $50 \%$ of the subjects responded correctly in the nonviolentbank and nonviolent-beach conditions, respectively. The smaller of these two figures, $47 \%$, is significantly different from the violent group's performance of $24 \%$ by a wide margin $(p<.01)$, whereas the two larger percentages obviously do not differ from each other.

In summary, this experiment showed that an unexpected event that is nonviolent in nature does not produce a similar retrograde effect for the critical item. Of course, it could be argued that the particular film segment we used had little action and few specific events to be encoded. A segment that was unexpected and unusual but more similar to the other conditions of information content might have produced a very different pattern of results. We cannot rule out this possibility.

\section{GENERAL DISCUSSION}

Taken together, these experiments provide support for the theory that exposure to mentally shocking events can cause retrograde amnesia for other events that occur a short period of time earlier. These effects occur whether retrograde amnesia is tested via recognition or recall. A promising explanation for these memory deficits is that mental shock disrupts the lingering processing necessary for full storage of information in memory. This idea resembles the formulation advanced long ago by Muller and Pilzecker (1900), who suggested that environmental stimuli initiate neural activity that endures for some length of time beyond the actual stimulus presentation. If this activity is left uninterrupted, an increasingly secure memory trace will be established. However, if the activity is interrupted, the memory trace will not be securely established.

Our results showed that impairment in memory occurred not only for an item seen immediately prior to the critical incident, but also for items occurring nearly 2 min earlier. Although this may seem to challenge the consolidation explanation, it can be accounted for by 
assuming that there are two consolidation processes, one for short-term traces and another for long-term traces (Deutsch \& Deutsch, 1966). Presumably, exposure to violence disrupts not only short-term consolidation but also long-term consolidation.

Another way to discuss the encoding deficit is in terms of level of processing of input items. Detterman (1975), after observing retrograde effects in recognition as well as recall of verbal materials, suggests that "the effect of the critical item is to change a subject's level of processing" (p. 627). In other words, items before the critical item might be processed differently. It is difficult to see why the items before the critical event should be processed differently by subjects who are treated identically. Perhaps the implicit assumption is that processing extends through time to the critical event, but it then becomes difficult to distinguish this notion from the more typical one of consolidation.

We do not mean to suggest that other theories of amnesia cannot explain the present results. For example, it may be that some form of the context encoding theories (see Stern, 1981) may be developed to accommodate these findings. It may be that subjects witnessing the shocking event are in a different emotional state at the time of retrieval and that state-dependent retrieval effects are operating. It is also possible that the mental shock has other effects that we have not measured here, such as the reconstruction or alteration of previously stored memory. For example, viewing the shooting of a young boy may cause a reconstruction of previously stored information about the robber (e.g., he is now a killer as well as a mere robber). The present materials do not, unfortunately, permit a test of this idea.

Whether the final explanation for the damaging effects of observing mentally shocking episodes is a cognitive one, an emotional one, or some combination, these results shed light on the speculation that certain substances released in affective states-for example, neurotransmitters such as norepinephrine-might have the effect of promoting memory storage (Kety, 1972). In a similar vein, other researchers have talked about the selection value of permanently retaining biologically crucial but unexpected events (Brown \& Kulik, 1977). The argument seems to be that it is possible that certain environmental presentations that are important for survival may produce an affective state that may "serve concurrently to reinforce and consolidate new and sig. nificant sensory patterns in the neocortex" (Kety, 1972, p. 73). If this hypothesis is correct, why do we and others (Clifford \& Hollin, 1981; Clifford \& Scott, 1978) show results indicating poorer retention for the details of mentally shocking events? It is entirely possible that memory for some aspect of the violent event (for example, the shooting incident in the film) is better consolidated or reinforced. This enhancement may be partially or solely responsible for the poorer retention of other details (such as the number on the football jersey). A test of this idea would necessarily involve a compari- son of memory for the identical item when it appeared in a context in which it was shocking vs. nonshocking, something that was not possible within the constraints of the present stimulus materials. On the other hand, it may be that norepinephrine or other substances, when injected alone, can promote memory storage, but cannot when released within the context of a particularly stressful event.

As we noted earlier, the superficial resemblance between the retrograde effects produced with and without physical insult to the brain do not necessarily indicate that the same mechanism is at work. In fact, there is at least one important difference: With clinical amnesia produced with electroconvulsive shock, drugs, anoxia, concussion, or disease, at the "eye of the storm" there is nothing. However, in the studies utilizing jolting material, the critical event itself is well recovered (Schacter \& Tulving, 1981; Kinsbourne, Note 1). It may well be, then, that our effects are more accurately described as von Restorff effects (see Wallace, 1965), situations in which an "outstanding" item is embedded within a list of otherwise homogeneous material. Invariably that item is well recalled. Although researchers have come to expect this memory enhancement for the critical item, the impact on surrounding items has been relatively unpredictable. Sometimes memory for surrounding items is enhanced (e.g., Jones \& Jones, 1942), sometimes it is impaired (Jenkins \& Postman, 1948), and sometimes any spread of effects is only temporarily observed (Brown \& Oxman, 1978). Smith and Stearns (1949) once tried to make sense of the disparate results by sug. gesting that the effect would depend upon the particular use that was made of the unusual item. Even then, however, they raised their hands in despair and concluded that what use a person makes of the unusual item "seems to result from factors quite difficult to specify" (Smith \& Stearns, 1949, p. 381). It was no wonder that Wallace (1965) was led to conclude that no definite conclusions could be reached as to the influence of an unusual item on surrounding material.

Whatever the theoretical explanation for the observed memory impairment, the results have important practical implications. They suggest that witnesses to emotionally traumatic events, such as crimes, accidents, or fires, may be less able to recall key events that occurred prior to the eruption of the trauma. In many crime situations, for example, there is often a period of observation prior to an act of violence during which information is available. Many laypersons believe that these observations are free from the deleterious effects of mental shock. In fact, even judges have been known to express the belief that the reliability of witnesses' memories is increased in the case of violent crimes (see cases cited by Wall, 1965; Woocher, 1977). The present research suggests otherwise.

One caution about these results is in order. In all three experiments, we have used only a single upsetting event, and we have shown that, in each case, memory for 
a peripheral detail is impaired. We have excluded some possible explanations for this robust result. Therefore, a needed step for future research is to further study the effects of upsetting events on memory in order to isolate the precise reason for memory impairment.

\section{REFERENCE NOTE}

1. Kinsbourne, M. Personal communication, 1981.

\section{REFERENCES}

Baddeley, A. D. The psychology of memory. New York: Basic Books, 1976.

Brown, A. S., \& Oxмan, M. Learning through participation: Effects of involvement and anticipation of involvement. American Journal of Psychology, 1978, 91, 161-172.

Brown, R., \& Kulik, J. Flashbulb memories. Cognition, 1977, 5, 73-99.

Clifford, B. R., \& Hollin, C. R. Effects of the type of incident and the number of perpetrators on eyewitness memory. Journal of Applied Psychology, 1981, 66, 364-370.

Clifford, B. R., \& ScotT, J. Individual and situational factors in eyewitness testimony. Journal of Applied Psychology, 1978, 63, 352-359.

Cotman, C. W., \& McGaugh, J. L. Behavioral neuroscience, an introduction. New York: Academic Press, 1980.

Detterman, D. K. The von Restorff effect and induced amnesia: Production by manipulation of sound intensity. Journal of Experimental Psychology: Human Learning and Memory, 1975, 1, 614-628.

Detterman, D. K., \& Ellis, N. R. Determinants of induced amnesia in short-term memory. Journal of Experimental Psychology, 1972, 95, 308-316.

Deutsch, J. A., \& Deutsch, D. Physiological psychology. Homewood, Ill: Dorsey, 1966.

Goldberg, E., Antin, S. P., Bilder, R. M., Jr., Gerstman, L. J., Hughes, J. E. O., \& MatTis, S. Retrograde amnesia: Possible role of mesencephalic reticular activation in long-term memory. Science, 1981, 213, 1392-1394.

Jenkins, W. O., \& Postman, L. Isolation and spread of effect in serial learning. American Journal of Psychology, 1948, 61, 214-221.
Jones, F. N., \& Jones, M. H. Vividness as a factor in learning lists of nonsense syllables. American Journal of Psychology, 1942, 55, 96-101.

KETY, S. S. Brain catecholamines, affective states, and memory. In J. L. McGaugh (Ed.), The chemistry of mood, motivation, and memory. New York: Plenum, 1972.

Muller, G. E., \& Pilzecker, A. Experimentalle beitrage zur lehre vom gedachtnis. Zeitschrift fur Psychologie, 1900, 1 , $1-300$.

Russell, W. R., \& Nathan, P. Traumatic amnesia. Brain, $1946,69,280-300$.

Saufley, W. H., \& Winograd, E. Retrograde amnesia and priority instructions in free recall. Journal of Experimental Psychology, 1970, 85, 150-152.

Schacter, D. L., \& Tulving, E. Amnesia and memory research. In L. S. Cermak (Ed.), Human memory and amnesia. Hillsdale, N. J: Erlbaum, 1981.

Schulz, L. S. Effects of high-priority events on recall and recognition of other events. Journal of Verbal Learning and Behavior, $1971,10,322-330$.

Smith, M. H., \& Stearns, E. G. The influence of isolation on the learning of surrrounding materials. American Journal of Psychology, 1949, 62, 369-381.

Squire, L. R., Slater, P. C., \& Chace, P. M. Retrograde amnesia: Temporal gradient in very long-term memory following ing electroconvulsive therapy. Science, 1975, 187, 77-79.

STE RN, L. D. A review of theories of human amnesia, Memory \& Cognition, 1981, 9, 247-262.

Tulving, E. Retrograde amnesia in free recall. Science, 1969 , 164, 88-90.

WALl, P. M. Eyewitness identification in criminal cases. Springfield, Ill: Thomas, 1965.

WALlaCe, W. P. Review of the historical, empirical, and theoretical status of the von Restorff phenomenon. Psychological Bulletin, 1965, 63, 410-424.

Whitty, C. W. M., \& ZAngwill, O. L. Amnesia (2nd edition). London: Butterworths, 1977.

WoOcher, F. D. Did your eyes deceive you?: Expert psychological testimony on the unreliability of eyewitness identification. Stanford Law Review, 1977, 29, 969-1031.

(Received for publication January 25, 1982; revision accepted March 16, 1982.) 